\title{
A Survey Towards Holistic Management of Schizophrenia
}

\author{
Pronab Ganguly, Ahmed A Moustafa \\ Western Sydney University, Sydney, Australia
}

\begin{abstract}
Holistic management of schizophrenia involves main stream pharmacological intervention, complimentary medicine intervention, therapeutic intervention, and other psychosocial factors, such as accommodation, education, job training, employment, relationship, friendship, exercise, overall well-being, smoking, substance abuse, suicide prevention, stigmatisation, recreation, entertainment, violent behaviour, arrangement of public trusteeship and guardianship, day-day-living skill, integration with community, management of overweight due to medications, and other health complications related to medications amongst others. Our review shows that there is no integrated survey by combining all these factors. We are conducting an international web based survey to evaluate the significance of all these factors and present them in a unified manner. We believe this investigation will contribute positively towards holistic management of schizophrenia. There will be two surveys. In the pharmacological intervention survey, five popular drugs for schizophrenia will be chosen and their efficacy as well as harmful side effects will be evaluated in a scale of $0-10$. This survey will be done by psychiatrists. In the second survey, each element of therapeutic intervention and psychosocial factors will be evaluated according to their significance in a scale of $0-10$. This survey will be done by care givers, psychologists, case managers, and case workers. For the first survey, we will contact the professional bodies of the psychiatrists in English speaking countries and request them to ask their members to participate in the survey. For the second survey, we will contact the professional bodies of clinical psychologist and care givers in English speaking countries and request them to ask their members to participate in the survey. Additionally for both the surveys, we will contact the relevant professionals through personal contact networks. For both the surveys, mean, mode, median, standard deviation, and net promoter score will be calculated for each factor and presented then in a statistically significant manner. Subsequently, each factor will be ranked according to their statistical significance. Additionally, country specific variation will be highlighted to identify the variation pattern. The results of these surveys will identify the relative significance of each type of pharmacological intervention, each type of therapeutic intervention, and each type of psychosocial factor. The determination of this relative importance will definitely contribute to the improvement in quality of life for individuals with schizophrenia.
\end{abstract}

Keywords: schizophrenia, holistic management, individualized treatment, antipsychotics, survey

\section{Background}

Schizophrenia is a brain disorder that impacts how a person acts, thinks, and perceives the world (Coyle, 2017). It is characterized by symptoms, such as delusions, hallucinations, disorganised speech, and diminished

Pronab Ganguly, Master, Ph.D. Student, School of Social Sciences and Psychology, Western Sydney University, Sydney, Australia.

Ahmed A Moustafa, Ph.D., Senior Lecturer, School of Social Sciences and Psychology, Western Sydney University, Sydney, Australia. 
emotional expression (Shenton et al., 1992). The cause of these symptoms has been attributed to a dysregulation of dopaminergic signalling (American Psychiatric Association, 2013). Schizophrenia is considered amongst the topmost 10 common disorders in the world (Mathers \& Loncar, 2006), as about one percentage of the general population suffers from schizophrenia (Simeone, Ward, Rotella, Collins, \& Windisch, 2015). Schizophrenia generally appears in the late teens or early adulthood. However, it may also appear in middle ages (Kirkbride, Fearon, \& Morgan, 2006). Generally, the early onset of schizophrenia is associated with severe positive and negative symptoms (Galletly et al., 2016). Schizophrenia was found to be more severe and more common in men than in women (Aleman, Kahn, \& Selten, 2003; McGrath, Saha, Chant, \& Welham, 2008). Schizophrenia is a chronic disorder that can be managed effectively with due care and management principles, in addition to antipsychotic medications. However, the likelihood of recovery is the highest, when schizophrenia is diagnosed and treated at its onset (Galletly et al., 2016). With medications and non-pharmacological therapy, many individuals with schizophrenia can live independently and have a satisfactory life, as we explain in the current study.

The long-term disability burden related to schizophrenia is far greater than any other mental disorders (Neil, Carr, \& Mihalopoulos, 2014). The direct cost of schizophrenia amounts to one-three percentage of national health care budget and is almost up to 20 percentage of the direct expenses of all types of mental health costs in most of the developed nations (Galletly et al., 2016). The indirect costs, such as independent accommodation, financial support, supported employment, and training, are comparable or even more than the direct costs, such as medications and hospital fees.

Importantly, one aim for treating this disorder is not only decreasing some of the symptoms, but also enhancing the quality of life of the patients (by having successful jobs, relationships among others). There are various quantitative studies on managing different symptoms associated with schizophrenia, such as a meta-analysis of population-based studies of premorbid intelligence and schizophrenia (Khandakera, Barnetta, Whitec, \& Jonesa, 2011), a quantitative magnetic resonance imaging study (Wible et al., 2001), and Royal Australian and New Zealand College of Psychiatrists clinical practice guidelines for the management of schizophrenia and related disorders (Galletly et al., 2016). However, there is no study till today that has combined all the factors associated with the holistic management of schizophrenia, which we address in this study.

\section{Possible Causes of Schizophrenia}

Here, we will first discuss the possible causes of schizophrenia symptoms and how knowing them can lead to a successful holistic management of the disorder. There is no single cause of schizophrenia though several factors have been identified (Park, Lee, Furnham, Jeon, \& Ko, 2017). As mentioned above, the probability of developing schizophrenia was found to be larger in males than females (Aleman et al., 2003; McGrath et al., 2008). It was also reported that the onset of schizophrenia occurs earlier in males than females (Cornblatt, Lenzenweger, Dworkin, \& Erlenmeyer-Kimling, 1985). Several studies have shown that schizophrenia may be hereditary (Matsumoto, Walton, Yamada, Kondo, Marek, \& Tajinda, 2017). It has been found that if one of the parents suffers from schizophrenia, the children have a 10 percentage chance of having that condition. Individuals with schizophrenia may become sensitive to any family tension, which may cause relapse (Buchanan, 2007). Stressful events might precede the onset of schizophrenia, as these incidents may act as triggering events in at-risk individuals (Nasrallah \& Hwang, 2009). Before any acute symptom of schizophrenia may become 
evident, individuals with schizophrenia may become anxious, irritable, and unable to concentrate. These symptoms cause difficulties with work and relationships may deteriorate.

Alcohol and drug use, particularly cannabis and amphetamine, might initiate psychosis in people susceptible to schizophrenia (Pogue-Geile \& Harrow, 1984; Li, Lu, Xiao, Li, He, \& Mei, 2014; Medhus, Rognli, Gossop, Holm, Mørland, \& Bramness, 2015). Substance abuse is strongly linked to the recurrence of schizophrenia symptoms (Moore, Mancuso, \& Slade, 2012). Individuals with schizophrenia use alcohol and other drugs more than the general population (Chiappelli, Chen, Hackman, \& Elliot Hong, 2017; Regier et al., 1990), which is detrimental to their treatment. A large number of individuals with schizophrenia have been found to smoke which contributes to poor physical health and well-being (Olfson, Gerhard, \& Huang, 2015). Methamphetamine, cannabis, and cocaine are found to trigger psychotic states in individuals with schizophrenia (Moustafa et al., 2017). Many studies have shown that methamphetamine can induce psychosis and schizophrenia, as reported in Thailand (Kittirattanapaiboon, Mahatnirunkul, Boonchareon, Thummawomg, Dumrongchai, \& Chutha, 2010) and Finland (Niemi-Pynttäri, Sund, Putkonen, Vorma, Wahlbeck, \& Pirkola, 2013). Substance abuse is much higher in individuals with schizophrenia than in the general population (Sara et al., 2015). In one research study (Barkus \& Murray, 2010), it was found that the use of cannabis and amphetamines significantly contributes to the risk of psychosis. Individuals with schizophrenia are generally sensitive to the psychotogenic effects of stimulant drugs, which act by releasing dopamine (M. -V. Seeman \& P. Seeman, 2014). As the symptoms of schizophrenia encompass almost all aspects of life, a holistic paradigm involving all the factors in management of daily living is very important.

\section{Methods of Review}

In our study, the eligibility criteria for selection of studies are their effectiveness in addressing issues related to holistic management of schizophrenia. The studies we considered are those which help manage symptoms of schizophrenia. Our search strategy included the following key words: schizophrenia, treatments, therapy, antipsychotic medication, management, quality of life, accommodation, employment, and holistic. Many of these searches were conducted in combination. For example, we searched experimental studies that include all of these key words: schizophrenia, social relationship, and therapy (or treatment). We examined articles carefully to make sure the goal of the study is addressing the treatment of some symptoms of schizophrenia. Studies that did not address this topic were excluded. We repeated the same search using other aspects of schizophrenia, as we show in Table 1. Throughout this review, we provide assessment of the validity of the findings. We also provide interpretations of the results. We have studied only major antipsychotic medications. We have searched studies in Pubmed, PsychInfo, and in Google Scholar. A decision tree for our method of articles selection is given in Figure 1. Out of 296 articles initially identified for the proposed review, 113 were removed for duplication. Again out of 183 studies, 19 articles were excluded for non-relevant design criteria, 15 articles were excluded for participant criteria, 15 articles were excluded for mode of intervention, 10 articles were excluded for psychosocial reasons, and five articles were excluded for other reason. Finally 119 studies were included for review. 

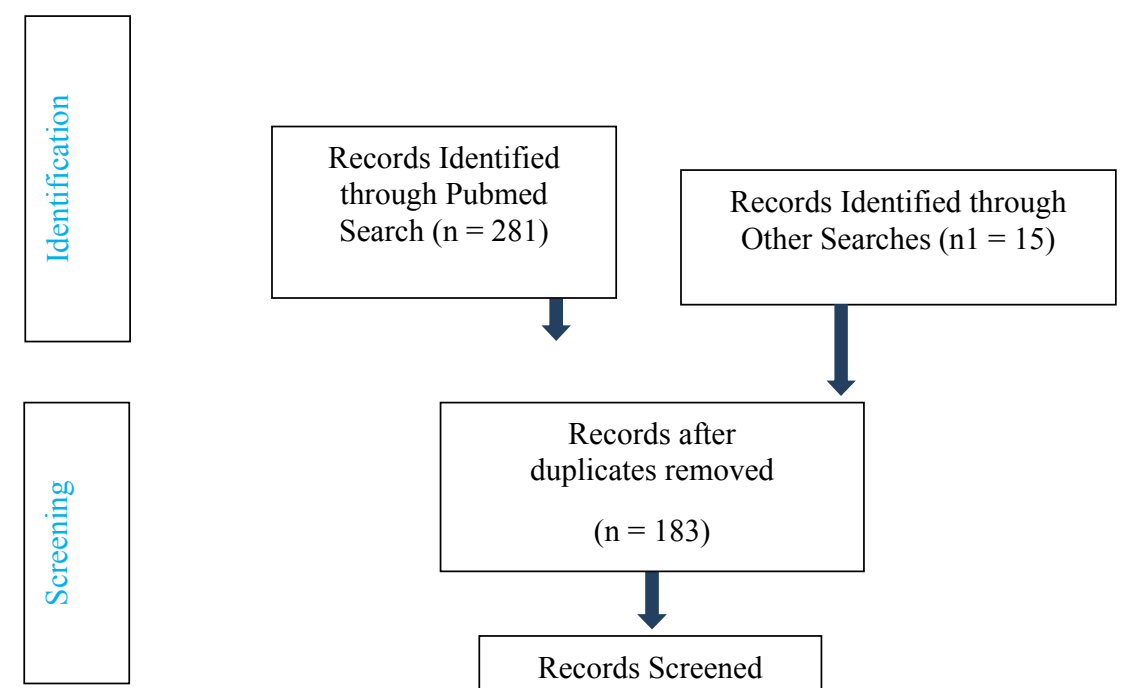

Records after

duplicates removed

$(\mathrm{n}=183)$
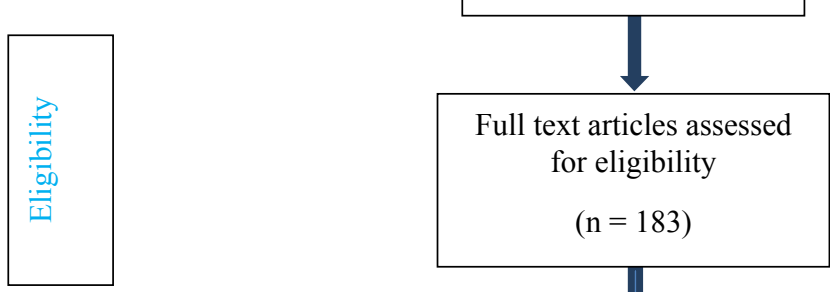

Full text articles assessed for eligibility

$(\mathrm{n}=183)$

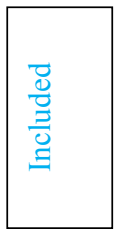

119 studies included for review

Figure 1. Decision tree for method of articles selection for review.

Table 1

The Relationship Between Different Symptoms and Problems Individuals With Schizophrenia Face, and How These Can Be Managed Using Pharmacological and Non-pharmacological Methods

\begin{tabular}{|l|l|l|}
\hline Symptoms related to schizophrenia & Treatment/Support options & Studies supporting treatment option \\
\hline $\begin{array}{l}\text { Hallucination and delusions which cause } \\
\text { inability to live independently }\end{array}$ & $\begin{array}{l}\text { Antipsychotic drugs and complimentary } \\
\text { intervention such as vitamin D or folic } \\
\text { acid; yoga as an add-on to medications; } \\
\text { Cognitive rehab; CBT as an add-on to } \\
\text { antipsychotics }\end{array}$ & $\begin{array}{l}\text { Mehta et al., 2016; Varambally et al., } \\
\text { 2012; Eack et al., 2011; Subramaniam et } \\
\text { al., 2012; Haddock et al., 1999; Kuipers et } \\
\text { al., 1997; Sensky et al., 2000; Beck, 1952; } \\
\text { Drury et al., 1996; Amminger et al., 2015; } \\
\text { Hill et al., 2013; Strauss, 2013; Thomas, } \\
\text { 1976; Waghorn et al., 2012) }\end{array}$ \\
\hline $\begin{array}{l}\text { Withdrawal from social life affecting } \\
\text { friendship and relationships }\end{array}$ & $\begin{array}{l}\text { Cognitive behaviour therapy; yoga as an } \\
\text { add-on to antipsychotic drugs which } \\
\text { improves cognitive impairment thus } \\
\text { leading to improved relationships }\end{array}$ & $\begin{array}{l}\text { (Turkington et al., 2000; Lewis et al., 2002; } \\
\text { Varambally et al., 2012; Iyer et al., 2011; } \\
\text { Ramsay et al., 2011) }\end{array}$ \\
\hline
\end{tabular}


Table 1 to be continued

\begin{tabular}{|c|c|c|}
\hline $\begin{array}{l}\text { Disorganised behaviour which affects day } \\
\text { to day life }\end{array}$ & $\begin{array}{l}\text { Cognitive behaviour therapy; yoga } \\
\text { therapy; antipsychotic medications and } \\
\text { complimentary interventions such as } \\
\text { vitamin D or folic acid supplements }\end{array}$ & $\begin{array}{l}\text { (Teesson et al., 2004; Morrison, 2009; } \\
\text { Cormac et al., 2002; Dickerson et al, } \\
\text { 2011) }\end{array}$ \\
\hline $\begin{array}{l}\text { Lack of sense of stability and security such } \\
\text { as homelessness }\end{array}$ & $\begin{array}{l}\text { Antipsychotics; CBT as an adjunct to } \\
\text { antipsychotics }\end{array}$ & $\begin{array}{l}\text { (Morrison, 2009; Jaeger et al., 2015; } \\
\text { Teesson et al., 1990; Folsom \& Jeste, } \\
\text { 2002; Coldwell et al., 2007; Girard et al., } \\
\text { 2017; Nelson et al., 2007) }\end{array}$ \\
\hline Lack of support groups & Along with antipsychotics, CBT and yoga & $\begin{array}{l}\text { (Gangadhar et al., 2012; Fontanella et al., } \\
\text { 2014) }\end{array}$ \\
\hline Lack of employment & $\begin{array}{l}\text { CBT, yoga, antipsychotic medications and } \\
\text { job training including vocational } \\
\text { intervention program }\end{array}$ & $\begin{array}{l}\text { (Kinoshita et al., 2013; Lysaker et al., } \\
\text { 2009; Killackey et al., 2006; Major et al., } \\
\text { 2010; Rinaldi et al., 2004; Bond et al., } \\
\text { 2012) }\end{array}$ \\
\hline Lack of education and training & $\begin{array}{l}\text { CBT, yoga and antipsychotic drugs that } \\
\text { improve cognitive impairment }\end{array}$ & $\begin{array}{l}\text { (Drake et al., 2012; Lysaker et al., 2009; } \\
\text { Vargas et al., 2014) }\end{array}$ \\
\hline Lack of recreation and entertainment & $\begin{array}{l}\text { CBT and Yoga-CBT addresses the issue } \\
\text { of cognitive dysfunction and yoga } \\
\text { contributes to sense of wellbeing that helps } \\
\text { in having recreation and entertainment }\end{array}$ & (Beck et al., 2005) \\
\hline Stigmatisation & CBT & (Koschorke et el., 2017; Świtaj et al., 2017 \\
\hline Lack of public guardianship & $\begin{array}{l}\text { CBT-in the absence of family support, } \\
\text { public guardianship is very important that } \\
\text { may be achieved by effective CBT }\end{array}$ & (Harvey et al., 2013) \\
\hline Suicide prevention & $\begin{array}{l}\text { CBT and antipsychotic drugs reduces } \\
\text { suicidal ideations }\end{array}$ & $\begin{array}{l}\text { (Hor et al., 2010; Mamo, 2007; Galletly et } \\
\text { al., 2016; Bateman et al., 2007; Challis et } \\
\text { al., 2013; Palmer et al., 2005; Preti et al., } \\
\text { 2009) }\end{array}$ \\
\hline Violent behaviour & CBT & $\begin{array}{l}\text { (Large et al., 2009; Erb et al., 2001; } \\
\text { Johnson, 2006) }\end{array}$ \\
\hline Lack of exercise & $\begin{array}{l}\text { CBT and yoga-they promote health } \\
\text { consciousness }\end{array}$ & (Galletly et al., 2016) \\
\hline Lack of integration with the community & Antipsychotic medications and CBT & (Eack et al., 2013; Eack et al., 2011) \\
\hline Lack of overall wellbeing & Yoga & $\begin{array}{l}\text { (Manjunath, 2009; Varambally et al., } \\
\text { 2012; Nagendra et al., 2000; } \\
\text { Walsh \& Roche, 1979) }\end{array}$ \\
\hline Substance abuse & Antipsychotics along with CBT or yoga & $\begin{array}{l}\text { (Moore et al., 2012; Drake et al., 2007; } \\
\text { Cather et al., 2017) }\end{array}$ \\
\hline
\end{tabular}

\section{Interventions for Schizophrenia}

In this section, we will discuss the various existing therapies used for treating schizophrenia symptoms as well as problems the patients face, such as unemployment, lack of education, and lack of social relationships.

\section{Pharmacological Intervention}

It has been observed that full recovery from the symptoms of schizophrenia occurs in six percentage of individuals with schizophrenia after a single episode of psychosis (Morgan et al., 2014). In 39 percentage of the patients, a deterioration of symptoms has been reported (Morgan et al., 2014). Approximately, about one in seven individuals with schizophrenia achieve total recovery (Jaaskelainen et al., 2013). Table 1 identifies the issues related to holistic management of schizophrenia and associated intervention options. 
The initial treatment of schizophrenia often includes various antipsychotic medications. The targets of antipsychotic medications are generally the symptoms of schizophrenia but not the root causes of it, such as stress and substance abuse (see above). As mentioned in Table 1, most antipsychotic drugs ameliorate hallucinations and delusions, while some attempt to also address the negative symptoms of schizophrenia. Antipsychotic medications are usually the only option for the treatment of schizophrenia. Most of antipsychotic treatments work by reducing the positive symptoms of schizophrenia through blocking dopamine receptors (Galletly et al., 2016).

In one research study by Girgis et al. (2011), 160 individuals with schizophrenia were randomized to clozapine or chlorpromazine treatment for up to two years. The adherence to clozapine was found to be higher than that of chlorpromazine. In another study conducted on 34 individuals with schizophrenia, it was found that there was no beneficial effect of clozapine over conventional antipsychotics (Woerner, Robinson, Alvir, Sheitman, Lieberman, \& Kane, 2003). McEvoy et al. (2006) found that a large percentage of individuals with schizophrenia discontinued treatment due to the inadequate efficacy of some antipsychotic drugs. An average daily dose of 523 and $600 \mathrm{mg}$ /day of clozapine has been found to be effective in the treatment of positive and negative symptoms in individuals with schizophrenia (McEvoy et al., 2006). Sanz-Fuentenebro et al. (2013) found that individuals with schizophrenia on clozapine continued their original treatment for a much longer period of time than patients on risperidone. Specifically, the retention rate for clozapine was 93.4 percentage whereas the retention rate for risperidone was 82.8 percentage. However, patients in the clozapine group normally have significant weight gain than those onrisperidone (Taylor \& McAskill, 2000).

In one study by Sahni, Chavan, Sidana, Kalra, and Kaur (2016), a total of 63 patients were selected and randomly allocated to either clozapine or risperidone. The two groups were similar on sociodemographic variables including age, sex, education level, occupation, income, family type, and marital status. The mean duration of illness was 19.39 months in the clozapine group, and 18.63 months in the risperidone group. There was a significant reduction of positive symptoms in both drugs. It was found that both clozapine and risperidone equally reduced positive symptoms whereas clozapine was much superior compared to risperidone in reducing negative symptoms. Clozapine has been found to reduce suicidal ideation in individuals with schizophrenia (Hennen \& Baldessarini, 2005); Along these lines, Hennen and Baldessarini (2005) reported that with administration of clozapine in chronically psychotic patients has led to a reduced suicidal ideation . In fact, it was concluded that long-term treatment with clozapine resulted in a three-fold reduction of risk of suicidal behaviours. Further, patients on clozapine are often administered metformin (500 $\mathrm{mg}$ twice daily) to lose weight. Aripiprazole is sometime given along with clozapine to manage weight and improve metabolic parameters (Muscatello et al., 2011). In one study, Muscatello et al. (2011) found that the administration of both aripiprazole and clozapine has led to a beneficial effect on the positive and general symptoms of individuals with schizophrenia, compared to clozapine alone.

Antipsychotic drugs also help ameliorate disoriented behaviour in day-to-day life. They are also used to improve cognitive impairment, which in turn improves relationship and contributes to the attainment of education and employment. Antipsychotic drugs help improve disoriented behaviour in day-to-day life. They are also used to improve relationships and enhance education (Drake et al., 2012; Lysaker, Davis, Bryson, \& Bell, 2009) and employment (Kinoshita et al., 2013). Table 1 summarizes the role of pharmacological intervention in the holistic management of schizophrenia. 


\section{Complementary Intervention and Diet}

Brown, Birtwistle, Roe, and Thompson (1999) found that the diets of schizophrenia patients contained more total fat and less fiber than the diets of a control group matched for age, gender, and education, although the intake of unsaturated fat was found to be similar in both groups. In another study, McCreadie et al. (1998) studied the dietary intake of 30 individuals with schizophrenia living in assisted-living facilities in Scotland as well as a control group matched for sex, age, smoking, and employment status. The majority of individuals with schizophrenia were overweight or obese, and saturated fat intake was higher than recommended in the diets for individuals with schizophrenia (Gothelf et al., 2002).

It was found that individuals with schizophrenia consumed less total fiber, retinol, carotene, vitamin $C$, vitamin E, fruit, and vegetables than the control group (Kalaydjian, Eaton, Cascella, \& Fasano, 2006).

McCreadie et al. (1998) studied dietary habits of 102 individuals with schizophrenia with special emphasis on fruit and vegetable intake and smoking behaviour. The study concluded that the patients (especially male patients) had poor dietary choices. Graham, Keefe, Lieberman, Calikoglu, Lansing, and Perkins (2015) suggested that administering vitamin $\mathrm{D}$ to individuals with schizophrenia ameliorates their negative symptoms. In another study by Strassnig, Singh, and Ganguli (2005), the dietary habits of a total of 146 adult community-dwelling individuals with schizophrenia were studied. It was observed that the patients consumed a higher quantity of food that includes protein, carbohydrate, and fat than that of a control group. Such habits can lead to cardiovascular diseases, type II diabetes, and systemic inflammation in individuals with schizophrenia (Kraft \& Westman, 2009). These diseases are related to a short lifespan in individuals with schizophrenia (Ran et al., 2007). In a research study by Joseph, Depp, Shih, Cadenhead, and Schmid-Schönbein (2017), it has been suggested that high-fibre diets can improve the immune and cardiovascular system, thereby, preventing premature mortality in schizophrenia.

As mentioned in Table 1, the administration of folic acid supplements may help ameliorate positive and negative symptoms in schizophrenia. Vitamin C, E, and B (including B12 and B6) were also found to be effective in managing schizophrenia symptoms (Brown \& Roffman, 2014). The administration of vitamin D helps improve daily living (Cieslak et al., 2014), as mentioned in Table 1. Nonetheless, additional studies are required in order to investigate whether there is a relationship between complimentary medications and schizophrenia. Table 1 summarizes the role of complementary intervention in the holistic management of schizophrenia.

\section{Cognitive Behaviour Therapy}

Cognitive behaviour therapy (CBT) is a therapeutic technique that helps modify undesirable mode of thinking, feeling, and behaviour. CBT involves practical self-help strategies, which are found to ameliorate positive symptoms in schizophrenia. CBT combines two kinds of therapies: "cognitive therapy" and "behavioural therapy". The combination of these two techniques often enables the patient to have healthy thoughts and behaviours. Morrison (2009) summarized the use of CBT in individuals with schizophrenia to address the primary symptoms of illness as well as social impairments. Morrison (2009) mentioned that many schizophrenia symptoms are resistant to pharmacological treatment and suggested CBT as an add-on to antipsychotics can be more effective than the administration of drugs alone. For example, several studies found that cognitive rehabilitation and CBT can ameliorate cognitive deficits and in turn positive symptoms (Eack, Hogarty, Greenwald, Hogarty, \& Keshavan, 2011; Subramaniam, Luks, Fisher, Simpson, Nagarajan, \& Vinogradov, 2012). 
There are many techniques to alter thoughts and behaviours using CBT. One research study described the key elements of CBT for schizophrenia (Tai \& Turkington, 2009) and concluded that various CBT techniques can be used effectively in schizophrenia. One of the techniques, known as cognitive restructuring, includes challenging the patient to come up with an evidence to prove that their beliefs are real. This technique assists the client to realise that they have delusions. This technique assists the patient to learn to identify and challenge negative thoughts and modify the faulty thoughts with more realistic and positive ones. CBT was also found to be effective for managing homelessness. As CBT ameliorates cognitive impairment, it helps improve relationship and contributes positively to entertainment. Behavioural therapy aims to assist the patient to learn to modify their behaviour. For example, they may rehearse conversational skills so that they can use these newly learned skills in social situations. CBT assists the patients in engaging in social circles which affects friendship and relationship as indicated in Table 1 .

There have been validation studies of CBT in schizophrenia over the last 15 years. In schizophrenia, CBT is one of the most commonly used therapy in the UK (generally in addition to medications) (Morrison, 2009). In fact, CBT has been recommended as first-line treatment by the UK national health service (NHS) for individuals with schizophrenia. Similarly, the American Psychiatric Association recommended CBT for individuals with schizophrenia (Jauhar, McKenna, Radua, Fung, Salvador, \& Laws, 2014). Recently, the US schizophrenia patient outcomes research team (PORT) has recommended CBT for patients who have persistent psychotic symptoms (Jauhar et al., 2014).

CBT was also found to be useful in reducing disorganised behaviour which affects daily living in individuals with schizophrenia. In one research study by Wykes, Steel, Everitt, and Tarrier (2008) in the United States and United Kingdom, it has been found that CBT is more preferred than other behavioural therapies. This study show that CBT ameliorates positive symptoms, negative symptoms, mood, and social anxiety. However, there was no effect on hopelessness. CBT sometimes includes the family of the patient in treatment session, which is why the patient and their carers usually welcome CBT. CBT brings the patient and their carers into a collaborative environment as a part of the treatment team and encourages them to participate actively in treatment . It has been found that hallucinations, delusions, negative symptoms, and depression are also treated with CBT (Sensky et al., 2000). CBT involves doing a homework which allows the patient and their carer to alleviate the distressing symptoms of schizophrenia. CBT encourages taking medications regularly and integrating with the community (Morrison, 2009). CBT has also been found to have enhanced effects when combined with antipsychotic medication (Pinto, La Pia, Menella, Giorgio, \& DeSimon, 1999), as compared to the administration of medications alone.

In one study (Sensky et al., 2000), 90 patients were treated using CBT for over nine months. The therapy resulted in significant reductions in positive and negative symptoms and depression. After a nine-month follow-up evaluation, patients receiving CBT continued to improve, unlike those who did not receive CBT. In order to apply CBT to schizophrenia, a deep understanding of the patient's symptoms should be developed first (Turkington, Kingdon, \& Weiden, 2006). Then, the issues related to positive and negative symptoms need to be addressed. CBT also helps reduce suicidal ideation and violent behaviour as well as encouraging individuals with schizophrenia to regularly exercise, integrate with the community, avoid stigmatisation, adopt public trusteeship and guardianship, and avoid substance abuse. Table 1 identifies the issues related to holistic management of schizophrenia and associated CBT intervention options. 


\section{Yoga Therapy}

Yoga therapy can also manage schizophrenia symptoms, often in combination with pharmacological medications (Jha, 2008). Pharmacological intervention alone might not produce all the desirable effects in managing schizophrenia symptoms, especially negative symptoms (Gangadhar \& Varambally, 2012). Yoga, as an add-on to antipsychotic medications, helps treat both positive and negative symptoms, more than medications alone. Furthermore, pharmacological interventions often produce obesity in schizophrenia (Gangadhar \& Varambally, 2012). Yoga therapy has been found to help reduce weight gain due to the administration of antipsychotic medications. Pharmacological interventions might cause endocrinological and menstrual dysfunction which may be positively treated by yoga therapy (Gangadhar \& Varambally, 2012). In a research study by Gangadhar and Varambally (2012), two groups of patients on antipsychotic medications were examined. In one group, yoga therapy was administered. In the other group, a set of physical exercises were applied. Both groups were trained for one month (at least 12 sessions). The yoga group showed better negative symptoms scores than the other group. Similarly, yoga therapy resulted in better effects on social dysfunction than the other group. Along these lines, Vancampfort et al. (2012) found that practicing yoga reduces psychiatric symptoms and improves the mental and physical quality of life, and also reduces metabolic risk.

The most probable explanation of the effectiveness of yoga therapy is the production of oxytocin in the body (Gangadhar \& Varambally, 2012). Oxytocin is a hormone which contributes to well-being. In one research study, 40 patients were administered oxytocin along with antipsychotic medications (Feifel, 2011). It was found that both negative and positive symptoms improved in those patients. The results of yoga therapy are manifolds. Yoga therapy can lead to a reduction in psychotic symptoms and depression, improvement in cognition, and an increase in quality of life. Table 1 identifies the issues related to holistic management of schizophrenia and associated yoga intervention options.

\section{Psychosocial Factors}

We have described and explained various factors to manage schizophrenia symptoms in a holistic manner. Although there are a multitude of research studies on pharmacological intervention, there are only few studies encompassing all the factors associated with holistic management of schizophrenia. Our study will attempt to provide a framework for holistic management of schizophrenia. Table 1 identifies the issues related to the holistic management of schizophrenia and intervention options for symptoms and issues most individuals with schizophrenia often face.

Based on our review (see Table 1), we found that different symptoms of schizophrenia (e.g., psychiatric symptoms, homelessness, unemployment, financial constraints, lack of education, poor relationship, among others) can be adequately addressed and managed using different methods (e.g., antipsychotics, CBT, yoga, among others). However, there are several issues like recreation and entertainment, public guardianship, and training for financial management that have not been adequately addressed in prior studies. Our study will provide a holistic account for how different symptoms in schizophrenia can be effectively managed.

Although most treatment studies focus on ameliorating positive and negative symptoms, other symptoms, such as homelessness and lack of education, equally impact the quality of life in individuals with schizophrenia. Thus, targeting these symptoms is of paramount importance. By doing so, we will be able to provide an individualized treatment for schizophrenia as well as increase the patients' participation in society. Galletly et al. (2016) provided a set of recommendations for the clinical management of schizophrenia. They adopted a 
somewhat holistic view of treating schizophrenia symptoms and problems the patients face, such as unemployment. This guideline emphasizes early intervention, physical health, psychosocial treatments, cultural considerations, and improving vocational outcomes as well as collaborative management and evidence-based treatment.

As shown in Table 1, even though different treatments can manage different schizophrenia symptoms, future research should investigate whether the combination of these treatments is effective, as it is possible that combining several treatments may not lead to the same effects of each therapeutic method administered alone. For example, although 85 percentage of individuals with schizophrenia are on government support (Galletly et al., 2016), they need to manage their finances. Group homes often provide financial management. However, in order to live independently, finance management is a problem for many patients. Independent living and integration with the community are areas which need further attention and work (Eack, Mesholam-Gately, \& Greenwald, 2013). Individuals with schizophrenia are often unable to run their daily chores. They need to be trained to preparea meal, wash clothes, and administer medications. Relationship is a problem for individuals with schizophrenia. As they are unable to participate in a conversation fluently, it is difficult for many patients to form a strong relationship. Their relationship, if ever successful, often becomes week over time and patients gradually become isolated. Since individuals with schizophrenia become withdrawn from most social activities, their friends and peers become disinterested and finally desert them. Individuals with schizophrenia often depend on close family support to survive. Table 1 describes ways to ameliorate such problems, which can help improve the quality of life of the patients. Entertainment and recreation are important element in everyday life. Individuals with schizophrenia have a fair bit of time in their hand as they are often not engaged in full-time job or any such activities. They get bored, and they need recreation as well, which is a key part of enhancing their quality of life. Hobbies and other recreational activities will help them alleviate boredom.

In our proposed framework for holistic management of schizophrenia, in addition to conventional pharmacological therapy, it is important to include other non-pharmacological interventions to assist the patients to obtain financial management, independent community living, independent living skill, insurance needs, public trustee and guardianship, relationship, friendship, and entertainment (Koschorke et al., 2017) as well as managealcohol and other drug issues, domestic violence, and any other health problems issues.

\section{Survey Methodology}

Our two international surveys will be online Internet based surveys. The survey results will be processed in two separate websites. The survey will be done amongst the professionals of English speaking countries. We are mainly targeting the English speaking countries, such as Australia, New Zealand, UK, North America, and Asia. We plan to write to the professional associations of the respective countries to request their members to participate in the survey. Additionally, we will request the potential respondents through our personal network. Considering the professional population of Australia, New Zealand, North America, Asia, and UK and average number survey responses, we are aiming a response number of around 100 for each type of survey. A sample size of 100 will be fairly representative of the opinions of the professionals for each type of survey. As the survey will be anonymous, we do not foresee any ethical issue related to the survey. Potential respondents will be assessed in country specific manner as they reflect the viewpoint of the belonging country.

\section{Proposed Pharmacological Survey Questionnaire}

The proposed questionnaire is described below: 
1. Country: Country drop down country list

2. Professional experience: $\square$ No. of Years

For the following drugs, please assess their effectiveness for treatment of schizophrenia as well as their side effects: in a scale of 0 to $10-0$ having least effect and 10 having most effect.

3. Generic name: aripiprazole; class: atypical antipsychotics

3a. Effectiveness in treating schizophrenia:

3b. Overweight due to medication:

3c. Effect on insulin resistance:

3d. Effect on sleep apnoea:

3e. Other harmful side effects:

4. Generic name: risperidone; class: atypical antipsychotics

4a. Effectiveness in treating schizophrenia:

$4 \mathrm{~b}$. Overweight due to medication:

4c. Effect on insulin resistance:

4d. Effect on sleep apnoea:

4e. Other harmful side effects:

5. Generic name: asenapine; class: atypical antipsychotics

5a. Effectiveness in treating schizophrenia:

$5 b$. Overweight due to medication:

5c. Effect on insulin resistance:

5d. Effect on sleep apnoea:

5e. Other harmful side effects:

6.Generic name: quetiapine; class: atypical antipsychotics

6a. Effectiveness in treating schizophrenia:

6b. Overweight due to medication:

6c. Effect on insulin resistance:

6d. Effect on sleep apnoea:

6e. Other harmful side effects:

7. Generic name: clozapine; class: atypical antipsychotics

7a. Effectiveness in treating schizophrenia:

7b. Overweight due to medication:

7c. Effect on insulin resistance:

7d. Effect on sleep apnoea:

7e. Other harmful side effects:

Please assess the effect of following complimentary medications in the treatment of schizophrenia in a scale of $0-10-0$ being the least effective and 10 being the most effective.

8. Vitamin B:

9. Folic Acid:

10. Fish Oil: 
11. Glycine:

12. Vitamin C:

13. Vitamin D:

14. Vitamin E:

\section{Proposed Non-pharmacological Survey Questionnaire}

The non-pharmacological survey questionnaire is described below:

1. Country: Country drop down list

2. Years of professional experience:

No. of Years

Please assess the following therapies in their effectiveness for treatment of schizophrenia in a scale from 0 to $10-0$ being least effective and 10 being most effective.

3. Cognitive Behaviour Therapy (CBT):

4. Yoga Therapy:

5. Tai Chi:

6. Art Therapy:

7. Music Therapy:

Please assess the importance of following factors in the overall management of schizophrenia in a scale of 0 to $10-0$ being least important and 10 being most important.

8. Stable and suitable accommodation:

9. Provision of education for future career:

10. Availability of job training:

11. Availability of employment:

12. Provision of recreation:

13. Provision of entertainment:

14. Imparting day to day living skill:

15. Arrangement of independent living skill:

16. Facility for integration with community:

17. Arrangement for suicide prevention:

18. Imparting knowledge about controlling violent behaviour:

19. Imparting knowledge about bad consequences of smoking:

20. Arrangement of knowledge about substance abuse:

21. Arrangement of coordination between various service providers:

22. Arrangement of public guardianship:

23. Arrangement of public trusteeship:

24. Organising facility for physical exercise:

25. Arrangement for familiarity with issues of stigmatisation:

26. Arrangement of healthy relationship:

27. Arrangement of friendship:

28. Arrangement of sense of overall well-being: 


\section{Survey Results Analysis}

After the survey responses are collected, we will calculate mean, median, mode, standard deviation, and net promoter score and we will rank the survey responses in order of their statistical significance.

\section{Net Promoter Score}

Net promoter score (Reichheld, 2003) is a significant element to capture practitioners' experience and used widely in various industries. A brief description of net promoter score is given here. Net promoter score (NPS) is practitioners' experience. It is a proven metric that forms the core of the experience programs over the world. For the questions asked, respondents answer this question on a scale from 0 to 10 , where 0 represents "least important" and 10 represents "highly important". Those who respond with 9-10 are called "promoters", 7-8 are "passives", and 0-6 are "detractors". The NPS is determined by subtracting the percentage of detractors from promoters. Respondents are grouped as follows:

(1) Promoters (score 9-10) are respondents who feel very strongly about the issue;

(2) Passives (score 7-8) are satisfied but do not feel very strongly about the issue;

(3) Detractors (score 0-6) are respondents who feel poorly about the issue.

Subtracting the percentage of detractors from the percentage of promoters yields the net promoter score, which can range from a low of -100 (if every practitioner is a detractor) to a high of 100 (if every practitioner is a promoter).

NPS will signify the type of preferences of the various factors in the survey responses.

\section{Ranking of the Factors}

In pharmacological survey response analysis, based on their statistical significance, each drug will be ranked in order of their popularity for effectiveness in treatment of schizophrenia as well as harmful side effects. This comparative study will highlight the efficacy of the chosen antipsychotic drugs in treatment of schizophrenia symptoms. In non-pharmacological survey response analysis, each therapy will be ranked in order of their preferences based on their statistical significance. This will signify the effectiveness of different therapies in holistic management of schizophrenia in order of preference and effectiveness. The other psychosocial factors, such as accommodation, education, and job training, will also be ranked in terms of their statistical significance. This will assist to allocate relative importance to the chosen factor in holistic management of schizophrenia.

\section{Discussion}

We have described and explained various factors to manage schizophrenia in a holistic manner. It may be mentioned that although there is widespread research and studies into pharmacological intervention, there are not many studies encompassing all the psychosocial factors associated with holistic management of schizophrenia. We have provided a framework for holistic management of schizophrenia and formulated a mechanism to evaluate the comparative significance of each factor in the holistic management of schizophrenia. Once we receive the responses of these two surveys, we will analyse them as described above. The results will assist to allocate relative importance to the respective factor controlling effective overall management of schizophrenia. This allocation of relative importance is very vital for effective management of schizophrenia. Thus this study will contribute positively to the improvement of quality of life for people with schizophrenia. 


\section{References}

Aleman, A., Kahn, R. S., \& Selten, J. P., (2003). Sex differences in the risk of schizophrenia: Evidence from meta-analysis. Archives of General Psychiatry, 60(6), 565-571.

American Psychiatric Association. (2013). Diagnostic and statistical manual of mental disorders (5th ed.). Arlington, VA: American Psychiatric Publishing.

Amminger, G. P., Schafer, R. M., Schlogelhofer, M., Klier, M. C., \& McGorry, D. P. (2015). Longer term outcome in the prevention of psychotic disorders by Vienna omega-3 study. Nature Communication, 7934. Retrieved from http://www.nature.com/ncomms/2015/150811/ncomms8934/full/ncomms8934.html

Barak, Y., Baruch, Y., Achiron, A., \& Aizenberg, D. (2008). Suicide attempts of schizophrenia patients: A case-controlled study in tertiary care. J Psychiatr Res, 42(10), 822-826. doi:10.1016/j.jpsychires.2007.09.002

Barkus, E., \& Murray, R. M. (2010). Substance use in adolescence and psychosis: Clarifying the relationship. Annual Review of Clinical Psychology, 6, 365-389. doi:10.1146/annurev.clinpsy.121208.131220

Bateman, K., Hansen, L., Turkington, D., \& Kingdon, D. (2007). Cognitive behavioral therapy reduces suicidal ideation in schizophrenia: Results from a randomized controlled trial. Suicide and Life-Threatening Behavior, 37(3), 284-290.

Beck, A. T. (1952). Successful outpatient psychotherapy of a chronic schizophrenic with a delusion based on borrowed guilt. Psychiatry, 15(3), 305-312.

Beck, A. T., \& Rector, N. A. (2005). Cognitive approaches to schizophrenia: Theory and therapy. Annual Review of Clinical Psychology, 1, 577-606.

Bond, G. R., Drake, E. R., \& Becker, D. (2012). Generalizability of the individual placement and support (IPS) model of supported employment outside the US. World Psychiatry, 11(2), 32-39.

Brown, H. E., \& Roffman, J. (2014). Vitamin supplementation in the treatment of schizophrenia. CNS Drugs, 28(7), 611-622.

Brown, S., Birtwistle, J., Roe, L., \& Thompson, C. (1999). The unhealthy lifestyle of people with schizophrenia. Psychological Medicine, 29(3), 697-701.

Buchanan, W. R. (2007). Persistent negative symptoms in schizophrenia: An overview. Schizophr Bull, 33(4), 1013-1022.

Cather, C., Pachas, G. N., Cieslak, K. M., \& Evins, A. E. (2017). Achieving smoking cessation in individuals with schizophrenia: Special considerations. CNS Drugs, 31(6), 471-481. doi:10.1007/s40263-017-0438

Challis, S., Neilssen, O., Harris, A., \& Large, M. (2013). Systematic meta-analysis of the risk factors for deliberate self-harm before and after treatment for first-episode psychosis. Acta Psychiatrica Scandinavica, 127(6), 442-454.

Chiappelli, J., Chen, S., Hackman, A., \& Elliot Hong, L. (2017). Evidence for differential opioid use disorder in schizophrenia in an addiction treatment population. Schizophrenia Research, 194, 26-31.

Cieslak, K., Feingold, J., Antonius, D., Walsh-Messinger, J., Dracxler, R., Rosedale, M., ... Malaspina, D. (2014). Low vitamin D levels predict clinical features of schizophrenia. Schizophrenia Research, 159(2-3), 543-545.

Coldwell, C. M., \& Bender, W. S. (2007). The effectiveness of assertive community treatment for homeless populations with severe mental illness: A meta-analysis. Am J Psychiatry, 164(3), 393-399. doi:10.1176/ajp.2007.164.3.393

Cormac, I., Jones, C., \& Campbell, C. (2002). Cognitive behaviour therapy for schizophrenia (Cochrane Review). Cochrane Library, (2).

Cornblatt, A. B., Lenzenweger, M. F., Dworkin, H. R., \& Erlenmeyer-Kimling, L. (1985). Positive and negative schizophrenic symptoms, attention, and information processing. Oxford Journals, Medicine \& Health, Schizophrenia Bulletin, 11(3), 397-408.

Coyle, J. T. (2017). Schizophrenia: Basic and clinical. Adv Neurobiol, 15, 255-280.

Dickerson, F. B., \& Lehman, A. F. (2011). Evidence-based psychotherapyfor schizophrenia: 2011 update. The Journal of Nervous and Mental Disease, 199(8), 520-526.

Drake, E. R., Bond, R. G., \& Becker, R. D. (2012). Individual placement and support: An evidence-based approach to supported employment. New York, NY: Oxford University Press.

Drake, R. E., Mueser, K. T., \& Brunette, M. F. (2007). Management of persons with co-occuring severe mental illness and substance use disorder: Program implications. World Psychiatry, 6(3), 131-136.

Drury, V., Birchwood, M., Cochrane, R., \& Macmillan, F. (1996). Cognitive therapy and recovery from acute psychosis: A controlled trial: I. Impact on psychotic symptoms. Br J Psychiatry, 169(5), 593-601.

Eack, S. M., Hogarty, G. E., Greenwald, D. P., Hogarty, S. S., \& Keshavan, M. S. (2011). Effects of cognitive enhancement therapy on employment outcomes in early schizophrenia: Results from a two-year randomized trial. Res Soc Work Pract, 21(1), 32-42. doi:10.1177/1049731509355812 
Eack, S. M., Mesholam-Gately, R. I., \& Greenwald, D. P. (2013). Negative symptom improvement during cognitive rehabilitation: Results from a 2-year trial of cognitive enhancement therapy. Psychiatry Research, 209(1), 21-26.

Erb, M., Hodgins, S., Freese, R., Muller-Isberner, R., \& Jockel, D. (2001). Homicide and schizophrenia: Maybe treatment does have a preventive effect. Crim Behav Ment Health, 11(1), 6-26.

Feifel, D. (2011). Is oxytocin a promising treatment for schizophrenia? Expert Rev Neurother, 11(2), 157-159.

Folsom, D., \& Jeste, D. V. (2002). Schizophrenia in homeless persons: A systematic review of the literature. Acta Psychiatr Scand, 105(6), 404-413.

Fontanella, C. A., Guada, J., Phillips, G., Ranbom, L., \& Fortney, J. C. (2014). Individual and contextual-level factors associated with continuity of care for adults with schizophrenia. Adm Policy Ment Health, 41(5), 572-587.

Galletly, C., Castle, D., Dark, F., Humberstone, V., Jablensky, A., Killackey, A., ... Tran, N. (2016). Royal Australian and New Zealand College of Psychiatrists clinical practice guidelines for the management of schizophrenia and related disorders. Aust N Z J Psychiatry, 50(5), 410-472.

Gangadhar, N., \& Varambally, S. (2012). Yoga therapy for schizophrenia. Int J Yoga, 5(2), 85-91.

Girard, V., Tinland, A., Bonin, J. P., Olive, F., Poule, J., Lancon, C., ... Simeoni, M. C. (2017). Relevance of a subjective quality of life questionnaire for long-term homeless persons with schizophrenia. BMC Psychiatry, 17(1), 72. doi:10.1186/s12888-017-1227-0

Girgis, R. R., Phillips, M. R., Li, X., Li, K., Jiang, H., Wu, C., ... Lieberman, J. A. (2011). Clozapine v. chlorpromazine in treatment-naive, first-episode schizophrenia: 9-year outcomes of a randomised clinical trial. Br J Psychiatry, 199(4), 281-288.

Gothelf, D., Falk, B., Singer, P., Kairi, M., Phillip, M., Zigel, L., ... Apter, A. (2002). Weight gain associated with increased food intake and low habitual activity levels in male adolescent schizophrenic inpatients treated with olanzapine. Am J Psychiatry, 159, 1055-1057.

Graham, K. A., Keefe, R. S., Lieberman, J. A., Calikoglu, A. S., Lansing, K. M., \& Perkins, D. O. (2015). Relationship of low vitamin D status with positive, negative and cognitive symptom domains in people with first-episode schizophrenia. Early Interv Psychiatry, 9(5), 397-405. doi:10.1111/eip.12122

Haddock, G., Tarrier, N., Morrison, A. P., Hopkins, R., Drake, R., \& Lewis, S. (1999). A pilot study evaluating the effectiveness of individual inpatient cognitive-behavioural therapy in early psychosis. Soc Psychiatry Psychiatr Epidemiol, 34(5), $254-258$.

Harvey, P. D., Stone, L., Lowenstein, D., Czaja, S. J., Heaton, R. K., Twamley, E. W., \& Patterson, T. L. (2013). The convergence between self-reports and observer ratings of financial skills and direct assessment of financial capabilities in patients with schizophrenia: More detail is not always better. Schizophrenia Research, 147(1), 86-90. doi:10.1016/j.schres.2013.02.018

Hennen, J., \& Baldessarini, R. J. (2005). Suicidal risk during treatment with clozapine: A meta-analysis. Schizophrenia Research, 73(2), 139-145.

Hill, S. K., Reilly, J. L., Keefe, R. S., Gold, J. M., Bishop, J. R., Gershon, E. S., ... Sweeney, J. A. (2013). Neuropsychological impairments in schizophrenia and psychotic bipolar disorder: Findings from the Bipolar-Schizophrenia Network on Intermediate Phenotypes (B-SNIP) study. American Journal of Psychiatry, 170(11), 1275-1284.

Hor, K., \& Taylor, M. (2010). Suicide and schizophrenia: A systematic review of rates and risk factors. Journal of Psychopharmacology, 24(4), 81-90.

Iyer, S. N., Mangala, R., Anitha, J., Thara, R., \& Malla, A. K. (2011). An examination of patient-identified goals for treatment in a first-episode programme in Chennai, India. Early Intervention in Psychiatry, 5(4), 360-365.

Jaaskelainen, E., Juola, P., Hirvonen, N., John, J., McGrath, J. J., Saha, S., ... Meittunen, J. (2013). A systematic review and meta-analysis of recovery in schizophrenia. Schizophrenia Bulletin, 39(6), 1296-1306.

Jaeger, M., Briner, D., Kawohl, W., Seifritz, E., \& Baumgartner-Nietlishach, G. (2015). Psychosocial functioning of individuals with schizophrenia in community housing facilities and the psychiatric hospital in Zurich. Psychiatry Res, 230(2), 413-418.

Jauhar, S., McKenna, P. J., Radua, J., Fung, E., Salvador, R., \& Laws, R. K. (2014). Cognitive-behavioural therapy for the symptoms of schizophrenia: Systematic review and meta-analysis with examination of potential bias. The British Journal of Psychiatry, 204(1), 20-29. doi:10.1192/bjp.bp.112.116285

Jha, A. (2008). Yoga therapy for schizophrenia. Acta Psychiatrica Scandinavica, 117(5), 397-403.

Johnson, M. (2006). National patient safety report. The Journal of Adult Protection, 8, 36-38.

Joseph, J., Depp, C., Shih, P. B., Cadenhead, K. S., \& Schmid-Schönbein, G. (2017). Modified mediterranean diet for enrichment of short chain fatty acids: Potential adjunctive therapeutic to target immune and metabolic dysfunction in schizophrenia? Front Neurosci, 11, 155. doi:10.3389/fnins.2017.00155 
Kalaydjian, A. E., Eaton, W., Cascella, N., \& Fasano, A. (2006). The gluten connection: The association between schizophrenia and celiac disease. Acta Psychiatrica Scandinavica, 113(2), 82-90.

Khandakera, M. G., Barnetta, H., Whitec, R. I., \& Jonesa, B. P. (2011). A quantitative meta-analysis of population-based studies of premorbid intelligence and schizophrenia. Schizophrenia Research, 132(2-3), 220-227.

Killackey, E. J., Jackson, H. J., Gleeson, J., Hickie, I. B., \& McGorry, P. D. (2006). Exciting career opportunity beckons! Early intervention and vocational rehabilitation in first-episode psychosis: Employing cautious optimism. Aust N Z J Psychiatry, 40(11-12), 951-962. doi:10.1080/j.1440-1614.2006.01918.x

Kinoshita, Y., Furukawa, T. A., Kinoshita, K., Honyashiki, M., Omori, I. M., Marshall, M., ... Kingdon, D. (2013). Supported employment for adults with severe mental illness. The Cochrane Database of Systematic Reviews, 9.

Kirkbride, J. B., Fearon, P., \& Morgan, C. (2006). Heterogeneity in incidence rates of schizophrenia and other psychotic syndromes: Findings from the 3-center AeSOP study. Archives of General Psychiatry, 63(3), 250-258.

Kittirattanapaiboon, P., Mahatnirunkul, S., Boonchareon, H., Thummawomg, P., Dumrongchai, U., \& Chutha, W. (2010). Long-term outcomes in methamphetamine psychosispatients after first hospitalisation. Drug and Alcohol Review, 29(4), 456-461.

Koschorke, M., Padmavati, R., Kumar, S., Cohen, A., Weiss, H. A., Chatterjee, S., ... Thornicroft, G. (2017). Experiences of stigma and discrimination faced by family caregivers of people with schizophrenia in India. Soc Sci Med, 178, 66-77.

Kraft, D. B., \& Westman, C. E. (2009). Schizophrenia, gluten, and low-carbohydrate, ketogenic diets: A case report and review of the literature. Nutrition \& Metabolism, 6, 10. doi:10.1186/1743-7075-6-10

Kuipers, E., Garety, P., Fowler, D., Dunn, G., Bebbington, P., Freeman, D., \& Hadley, C. (1997). London-East Anglia randomised controlled trial of cognitive-behavioural therapy for psychosis. I: Effects of the treatment phase. Br J Psychiatry, 171, 319-327.

Large, M., Smith, G., \& Nielssen, O. (2009). The relationship between the rate of homicide by those with schizophrenia and the overall homicide rate: A systematic review and meta-analysis. Schizophrenia Research, 112, 123-129.

Lewis, S., Tarrier, N., \& Haddock, G. (2002). Randomised controlled trial of cognitive-behavioural therapy in early schizophrenia: Acute-phase outcomes. British Journal of Psychiatry, 181(suppl. 43), 91-97.

Li, H. B., Lu, Q., Xiao, E. H., Li, Q. Y., He, Z., \& Mei, X. L. (2014). Methamphetamine enhances the development of schizophrenia in first-degree relatives of patients with schizophrenia. Can J Psychiatry, 59(2), 107-113. doi:10.1177/070674371405900206

Lysaker, P. H., Davis, L. W., Bryson, G. J., \& Bell, M. D. (2009). Effects of cognitive behavioral therapy on work outcomes in vocational rehabilitation for participants with schizophrenia spectrum disorders. Schizo Res, 107, 186-191.

Major, B. S., Hinton, M. F., Flint, A., Chalmers-Brown, A., McLoughlin, K., \& Johnson, S. (2010). Evidence of the effectiveness of a specialist vocational intervention following first episode psychosis: A naturalistic prospective cohort study. Soc Psychiatry Psychiatr Epidemiol, 45(1), 1-8. doi:10.1007/s00127-009-0034-4

Mamo, D. C. (2007). Managing suicidality in schizophrenia. Can J Psychiatry, 52(6), 59-70.

Manjunath, R. B. (2009). Efficacy of yoga therapy as an add-on treatment for in-patients and out-patients with functional psychotic disorder (Dissertation, National Institute of Mental Health and Neurosciences, Bangalore).

Mathers, C. D., \& Loncar, D. (2006). Projections of global mortality and burden of disease from 2002 to 2030. PLoS Medicine, $3(11)$, e 442 .

Matsumoto, M., Walton, N. M., Yamada, H., Kondo, Y., Marek, G. J., \& Tajinda, K. (2017). The impact of genetics on future drug discovery in schizophrenia. Expert Opin Drug Discov, 12(7), 673-686.

McCreadie, R. (2003). Diet, smoking, and cardiovascular risk in people with schizophrenia: Descriptive study. British Journal of Psychiatry, 183, 534-539.

McCreadie, R., MacDonald, E., Blackock, C., Tilak-Singh, D., Wiles, D., Halliday, J., \& Patterson, J. (1998). Dietary intake of schizophrenic patients in Nithsdale, Scotland: Case-control study. BMJ, 317, 784-785.

McEvoy, J. P., Lieberman, J. A., Stroup, T. S., Davis, S. M., Meltzer, H. Y., Rosenheck, R. A., ... Swartz, M. S. (2006). Effectiveness of clozapine versus olanzapine, quetiapine, and risperidone in patients with chronic schizophrenia who did not respond to prior atypical antipsychotic treatment. Am J Psychiatry, 163, 600-610.

McGrath, J. L., Saha, S., Chant, D., \& Welham, J. (2008). Schizophrenia: A concise overviewof incidence, prevalence, and mortality. Epidemiologic Reviews, 30, 67-76.

Medhus, S., Rognli, E. B., Gossop, M., Holm, B., Mørland, J., \& Bramness, J. G. (2015). Amphetamine-induced psychosis: Transition to schizophrenia and mortality in a small prospective sample. The American Journal on Addictions, 24(7), 586-589. 
Mehta, U. M., Keshavan, M. S., \& Gangadhar, B. N. (2016). Bridging the schism of schizophrenia through yoga—Review of putative mechanisms. Int Rev Psychiatry, 28(3), 254-264. doi:10.1080/09540261.2016.1176905

Moore, E., Mancuso, S. G., \& Slade, T. (2012). The impact of alcohol and illicit drugs on people with psychosis: The second Australian national survey of psychosis. Australian and New Zealand Journal of Psychiatry, 46, 864-878.

Morgan, V. A., McGrath, J. J., Jablensky, A., Badcock, J. C., Waterreus, A., Bush, R., .. Mackinnon, A. (2014). Psychosis prevalence and physical, metabolic and cognitive co-morbidity: Data from the second Australian national survey of psychosis. Psychological Medicine, 44(10), 2163-2176.

Morrison, A. K. (2009). Cognitive behavior therapy for people with schizophrenia. Psychiatry (Edgmont), 6(12), 32-39.

Moustafa, A. A., Salama, M., Peak, R., Tindle, R., Salem, A., Keri, S., ... Mohamed, W. (2017). Interactions between cannabis and schizophrenia in humans and rodents. Reviews in the Neuroscience, 28(7), 811-823.

Muscatello, M. R. L., Bruno, A., Pandolfo, G., Micò, U., Scimeca, G., Di Nardo, F., ... Zoccali, R. A. (2011). Effect of aripiprazole augmentation of clozapine in schizophrenia: A double-blind, placebo-controlled study. Schizophr Res, 127(1-3), 93-99. doi:10.1016/j.schres.2010.12.011

Myin-Germeys, I., \& Van Os, J. (2007). Stress-reactivity in psychosis: Evidence for an affective pathway to psychosis. Clinical Psychology Review, 27(4), 409-424.

Nagendra, H. R., Telles, S., \& Naveen, K. V. (2000). An integrated approach of yoga therapy for the management of schizophrenia. Final Report submitted to Dept. of ISM and H, Ministry of Health and Family Welfare, Government of India, New Delhi.

Nasrallah, H., \& Hwang, M. (2009). Psychiatric and physical comorbidity in schizophrenia. A Psychiatric Clinic, 32(4), $719-914$.

Neil, A. L., Carr, V. J., \& Mihalopoulos, C. (2014). What difference a decade? The costs of psychosis in Australia in 2000 and 2010: Comparative results from the first and second Australian national surveys of psychosis. Australian and New Zealand Journal of Psychiatry, 48(3), 237-248.

Nelson, G., Aubry, T., \& Lafrance, A. (2007). A review of the literature on the effectiveness of housing and support, assertive community treatment, and intensive case management interventions for persons with mental illness who have been homeless. Am J Orthopsychiatry, 77(3), 350-361. doi:10.1037/0002-9432.77.3.350

Niemi-Pynttäri, J. A., Sund, R., Putkonen, H., Vorma, H., Wahlbeck, K., \& Pirkola, S. P. (2013). Substance-induced psychoses converting into schizophrenia: A register-based study of 18,478 Finnish inpatient cases. J Clin Psychiatry, 74(1), 94-99. doi: $10.4088 / \mathrm{JCP} .12 \mathrm{~m} 07822$

Olfson, M., Gerhard, T., \& Huang C. (2015). Premature mortality among adults with schizophrenia in the United States. JAMA Psychiatry, 72(12), 1172-1181.

Palmer, B. A., Pankratz, V. S., \& Bostwick, J. M. (2005). The lifetime risk of suicide in schizophrenia: A reexamination. Archives of General Psychiatry, 62(3), 247-253.

Park, S., Lee, M., Furnham, A., Jeon, M., \& Ko, Y. M. (2017). Lay beliefs about the causes and cures of schizophrenia. Int J Soc Psychiatry, 63(6), 518-524.

Pinto, A., La Pia, S., Menella, R., Giorgio, D., \& DeSimone, L. (1999). Cognitive behavioural therapy and clozapine for patients with schizophrenia. Psychiatric Services, 50(7), 901-904.

Pogue-Geile, F. M., \& Harrow, M. (1984). Negative and positive symptoms in schizophrenia and depression: A followup. Oxford Journals, Medicine \& Health, Schizophrenia Bulletin, 10(3), 371-387.

Preti, A., Meneghelli, A., Pisano, A., Cocchi, A., \& Programma, T. (2009). Risk of suicide and suicidal ideation in psychosis: Results from an Italian multi-modal pilot program on early intervention in psychosis. Schizophr Res, 113(2-3), 145-150. doi:10.1016/j.schres.2009.06.007

Ramsay, C. E., Broussard, B., Goulding, S. M., Cristofaro, S., Hall, D., Kaslow, N. J., ... Compton, M. T. (2011). Life and treatment goals of individuals hospitalized for first-episode nonaffective psychosis. Psychiatry Research, 189(3), 344-348.

Ran, M. S., Chen, E. Y., Conwell, Y., Chan, C. L., Yip, P. S., Xiang, M. Z., \& Caine, E. D. (2007). Mortality in people with schizophrenia in rural China: 10-year cohort study. Br J Psychiatry, 190, 237-242. doi:10.1192/bjp.bp.106.025155

Regier, D. A., Farmer, M. E., Rae, D. S., Locke, B. Z., Keith, S. J., Judd, L. L., \& Goodwin, F. K. (1990). Comorbidity of mental disorders with alcohol and other drug abuse. JAMA, 264(19), 2511-2518.

Reichheld, F. F. (2003). The one number you need to grow. Harvard Business Review, 81(12), 46-54.

Rinaldi, M., McNeil, K., Firn, M., Koletsi, M., Perkins, R., \& Singh, S. P. (2004). What are the benefits of evidence based supported employment for patients with first-episode psychosis? Psychiatric Bulletin, 28(8), 281-284. 
Sahni, S., Chavan, S. B., Sidana, A., Kalra, P., \& Kaur, G. (2016). Comparative study of clozapine versus risperidone in treatment-naive, first-episode schizophrenia: A pilot study. Indian J Med Res, 144(5), 697-703.

Sanz-Fuentenebro, J., Taboada, D., Palomo, T., Aragües, M., Ovejero, S., Del Alamo, C., \& Molina, V. (2013). Randomized trial of clozapine vs. risperidone in treatment-naive first-episode schizophrenia: Results after one year. Schizophr Res, 149, 156-161.

Sara, G. E., Large, M. M., Matheson, S. L., Burgess, P. M., Malhi, G. S., Whiteford, H. A., \& Hall, W. (2015). Stimulant use disorders in people with psychosis: A meta-analysis of rate and factors affecting variation. Australian and New Zealand Journal of Psychiatry, 49(2), 106-117.

Seeman, M. V., \& Seeman, P. (2014). Is schizophrenia a dopamine supersensitivity psychotic reaction? Progress in Neuro-Psychopharmacology and Biological Psychiatry, 48(3), 155-160.

Sensky, T., Turkington, D., Kingdon, D., Scott, J. L., Scott, J., Siddle, R. O., ... Barnes, R. E. T. (2000). A randomized controlled trial of cognitive-behavioural therapy for persistent symptoms in schizophrenia resistant to medication. Archives of General Psychiatry, 57, 165-172.

Shenton, E. M., Kikinis, R., Jolesz, A. F., Pollak, D. S., LeMay, M., Wible, G., .. McCarley, W. R. (1992). Abnormalities of the left temporal lobe and thought disorder in schizophrenia-A quantitative magnetic resonance imaging study. $N$ Engl J Med, 327(9), 604-612.

Simeone, J. C., Ward, A. J., Rotella, P., Collins, J., \& Windisch, R. (2015). An evaluation of variation in published estimates of schizophrenia prevalence from 1990-2013: A systematic literature review. BMC Psychiatry, 15(1), 193.

Strassnig, M., Singh, B. J., \& Ganguli, R. (2005). Dietary intake of patients with schizophrenia. Psychiatry (Edgmont), 2(2), 31-35.

Strauss, J. (2013). Reconceptualizing schizophrenia. Schizophrenia Bulletin, 40(suppl. 2), S97-S100.

Subramaniam, K., Luks, T. L., Fisher, M., Simpson, G. V., Nagarajan, S., \& Vinogradov, S. (2012). Computerized cognitive training restores neural activity within the reality monitoring network in schizophrenia. Neuron, 73(4), 842-853. doi:10.1016/j.neuron.2011.12.024

Świtaj, P., Grygiel, P., Chrostek, A., Nowak, I., Wciórka, J., \& Anczewska, M. (2017). The relationship between internalized stigma and quality of life among people with mental illness: Are self-esteem and sense of coherence sequential mediators? Qual Life Res, 26(9), 2471-2478. doi:10.1007/s11136-017-1596-3

Tai, S., \& Turkington, D. (2009). The evolution of cognitive behavior therapy for schizophrenia: Current practice and recent developments. Schizo Bull, 35(5), 865-873.

Taylor, D. M., \& McAskill, R. (2000). Atypical antipsychotics and weight gain-A systematic review. Acta Psychiatr Scand, 101(6), 416-32.

Teesson, M., Hall, W., Lynskey, M., \& Degenhardt, L. (2000). Alcohol and drug-use disorders in Australia: Implications of the national survey of mental health and wellbeing. Australian and New Zealand Journal of Psychiatry, 34(2), 206-213.

Teesson, M. L., Hodder, T., \& Buhrich, N. (2004). Psychiatric disorders in homeless men and women in inner Sydney. Australian and New Zealand Journal of Psychiatry, 38, 162-168.

Thomas, D. (1976). Quantitative studies of schizophrenic behavior. Behavioural Processes, 1(4), 347-372.

Turkington, D., \& Kingdon, D. (2000). Cognitive-behavioural techniques for general psychiatrists in the management of patients with psychoses. British Journal of Psychiatry, 177(2), 101-106.

Turkington, D., Kingdon, D., \& Weiden, P. J. (2006). Cognitive behavior therapy for schizophrenia. Am J Psychiatry, 163(3), 365-373.

Vancampfort, D. L., Probst, M., Helvik Skjaerven, L., Catalán-Matamoros, D., Lundvik-Gyllensten, A., Gómez-Conesa, A., ... De Hert, M. (2012). Systematic review of the benefits of physical therapy within a multidisciplinary care approach for people with schizophrenia. Physical Therapy, 92(1), 1-13.

Varambally, S., Gangadhar, B. N., Thirthalli, J., Jagannathan, A., Kumar, S., Venkatasubramanian, G., ... Nagendra, H. R. (2012). Therapeutic efficacy of add-on yogasana intervention in stabilized outpatient schizophrenia: Randomized controlled comparison with exercise and waitlist. Indian J Psychiatry, 54(3), 227-232. doi:10.4103/0019-5545.102414

Vargas, G., Strassnig, M., Sabbag, S., Gould, F., Durand, D., Stone, L., ... Harvey, P. D. (2014). The course of vocational functioning in patients with schizophrenia: Re-examining social drift. Schizophr Res Cogn, 1(1), e41-e46. doi:10.1016/j.scog.2014.01.001

Waghorn, G., Saha, S., Harvey, C., Morgan, V. A., Waterrus, A., Bush, R., ... McGrath, J. J. (2012). Earning and learning' in those with psychotic disorders: The second Australian national survey of psychosis. Australian and New Zealand Journal of Psychiatry, 46(8), 774-785. 
Walsh, R., \& Roche, L. (1979). Precipitation of acute psychotic episodes by intensive meditation in individuals with a history of schizophrenia. Am J Psychiatry, 136(8), 1085-1086.

Wible, G. C., Anderson, J., Shenton, E. M., Kricun, A., Hirayasu, Y., Tanaka, S., .. McCarley, W. R. (2001). Prefrontal cortex, negative symptoms, and schizophrenia: An MRI study. Psychiatry Res, 108(2), 65-78.

Woerner, M. G., Robinson, D. G., Alvir, J. M., Sheitman, B. B., Lieberman, J. A., \& Kane, J. M. (2003). Clozapine as a first treatment for schizophrenia. Am J Psychiatry, 160(8), 1514-1516.

Wykes, T., Steel, C., Everitt, B., \& Tarrier, N. (2008). Cognitive behavior therapy for schizophrenia: Effect sizes clinical models, and methodological rigor. Schizophr Bull, 34(3), 523-537. 